\title{
Erratum to: Pulmonary vein anatomical variation during videothoracoscopy-assisted surgical lobectomy
}

\author{
Irene Asouhidou ${ }^{1,3} \cdot$ Theodoros Karaiskos $^{2} \cdot$ Konstantinos Natsis $^{3}$
}

Published online: 23 May 2017

(C) Springer-Verlag France 2017

\section{Erratum to: Surg Radiol Anat (2017) 39:229-231}

DOI 10.1007/s00276-016-1719-5

In the original publication of the article, the list of author names was incorrect. Author names were inverted with the surname preceding first name.

The correct author names are listed: Irene Asouhidou, Theodoros Karaiskos, Konstantinos Natsis

The online version of the original article can be found under doi:10.1007/s00276-016-1719-5.

Irene Asouhidou

iasouh@aol.com

1 Department of Anesthesiology, G. Papanikolaou Hospital, 15-17 Agiou Evgeniou str, 55133 Thessaloniki, Greece

2 Department of Cardiothoracic Surgery, G. Papanikolaou Hospital, Thessaloniki, Greece

3 Department of Anatomy, Aristotle University of Thessaloniki, Thessaloniki, Greece 